\title{
Strengthening of Traditional Knowledge for Sustainable Forest Management: Case in Seram Island, Mollucas, Indonesia
}

\author{
Marthina Tjoa $^{1, *}$, Didik Suharjito ${ }^{2}$, Hariadi Kartodihardjo ${ }^{2}$, Endriatmo Soetarto ${ }^{3}$ \\ ${ }^{1}$ Department of Forestry, Faculty of Agricultural, University of Pattimura, Indonesia \\ ${ }^{2}$ Faculty of Forestry, Bogor Agricultural University, Bogor, Indonesia \\ ${ }^{3}$ Faculty of Human Ecology, Bogor Agricultural University, Bogor, Indonesia
}

Copyright $\bigcirc 2018$ by authors, all rights reserved. Authors agree that this article remains permanently open access under the terms of the Creative Commons Attribution License 4.0 International License

\begin{abstract}
Forest management systems of indigenous people have undergone many changes due to a variety of interests which is a form of adaptation. Various impacts of change can undermine custom values and rules. The purpose of this research is to facilitate the strengthening of custom system in forest resource management. This research used descriptive qualitative method with PAR (Participatory Action Research) approach. PAR is conducted by constructing meaning constructs together between researchers based on the concepts of experts and concepts of indigenous peoples on sustainable forest management and its issues. The results showed changes in the indigenous system implementation techniques, but basic values are preserved. These basic values serve as guidelines for action to achieve sustainable forest management and utilization.
\end{abstract}

Keywords Forest Management, Customary System, Value of Traditional Knowledge

\section{Introduction}

The management of forest resources and the existence of indigenous peoples have received considerable attention. The concern is driven by a desire to understand social and ecological relationships in the management and utilization of sustainable forest resources [1,2]. In Indonesia, these studies are evolving because the implementation of sustainable forest management policies is not yet optimal. There are still differences in perceptions between forest communities and forest policy makers [3] Policy makers often do not pay attention to conditions at the community level [4].

Sustainable forest management has been practiced by indigenous peoples since tens or even hundreds of years ago and is still implemented today. This is because indigenous peoples understand the importance of forests as a place of livelihood, resource providers, conservation areas, water providers and other functions. This application is also reinforced by binding customary rules such as the imposition of sanctions and fines for people who are proven wrong.

Indigenous peoples have tried to keep forests the only source of livelihood that can be passed on to the next generation [3]. Various studies have shown that communities have the capacity to manage forests sustainably [5-8]. However, customary systems need to be ascertained because people's lives are not static, they are either willing or forced to adapt to socio-economic changes [9]. In addition deforestation has threatened sustainable forest use in forest-dependent communities as their livelihood [10].

The changes that occur are a requirement of indigenous peoples to adapt customary systems to continue to grow. Changes to customary systems can be changes in values, norms or rules developed by the community. The custom system that is maintained based on traditional knowledge is a learning process of strengthening the system.

Thus, the purpose of this research is to facilitate the process of strengthening local knowledge of indigenous peoples for sustainable forest management. The strengthening process is conducted with the aim of determining the certainty of customary systems in supporting sustainable forest management.

\section{Materials and Methods}

\subsection{Theoretical Framework}

The approach of cultural ecological theory [11] is used to look at the dialectical connections of indigenous peoples 
and the environment of forest resources. Indigenous peoples have traditional wisdom values formed from repeated interactions between communities and forest resources. Forests as a unity of the cultural environment become the foundation of indigenous life to sustain its life system. Culture and environment have a reciprocal relationship. Culture is used to understand the environment, but on the other hand the environment gives effect to the formation of culture. The network of interactions within the social structure is governed by a system of values, norms, rules and cultural patterns. The already strong norm is called a pranata used for guidelines to behave with others in order to achieve harmony and order.

Social change in the cultural dialectic of society is a process that will take place continuously as the development of culture. According to Geertz [12] culture is "the pattern of all-encompassing meanings or meanings in historically transmitted symbols, a system of conceptions inherited in symbolic forms in which human beings communicate, preserve and Develop their knowledge and attitudes toward life ".

Traditional knowledge deals with data and information about the experience of the community to deal with its problems and needs and solutions. Traditional knowledge is not subordinated to external knowledge, unless the society perceives that outside knowledge can satisfy itself and local knowledge fails to bring about change. Traditional knowledge can be seen as a local initiative applied by the community in the form of local wisdom to overcome various problems.
Characteristics that strengthen local wisdom that is able to survive the outside culture, has the ability to accommodate the elements of outside culture, has the ability to integrate elements of external culture into the original culture, have the ability to control, able to give direction to the development of culture.

Preserving and using traditional knowledge does not mean simply repeating past techniques, but rather understanding the basic values of this knowledge. Traditional knowledge is both dynamic and adaptive, allowing its users to combine tested innovations over long periods of time to achieve local socio-economic and environmental sustainability.

\subsection{Research Sites}

The PAR method was used in the research process in Honitetu Village, Inamosol Sub-District, and West Seram District of Maluku Province (Figure 1). Honitetu village was chosen as the PAR case with the reason of having a history of forest management based on customary system that is maintained. However, external intervention on indigenous territories and adaptation to the changing needs of life poses various problems in forest management. The PAR approach becomes important for understanding the complexity of the problem followed by taking action to correct the problem. Research was also conducted in Kamariang, Mornaten, Uwen and Lokki villages to obtain a broader description of sustainable forest management in Seram Island.

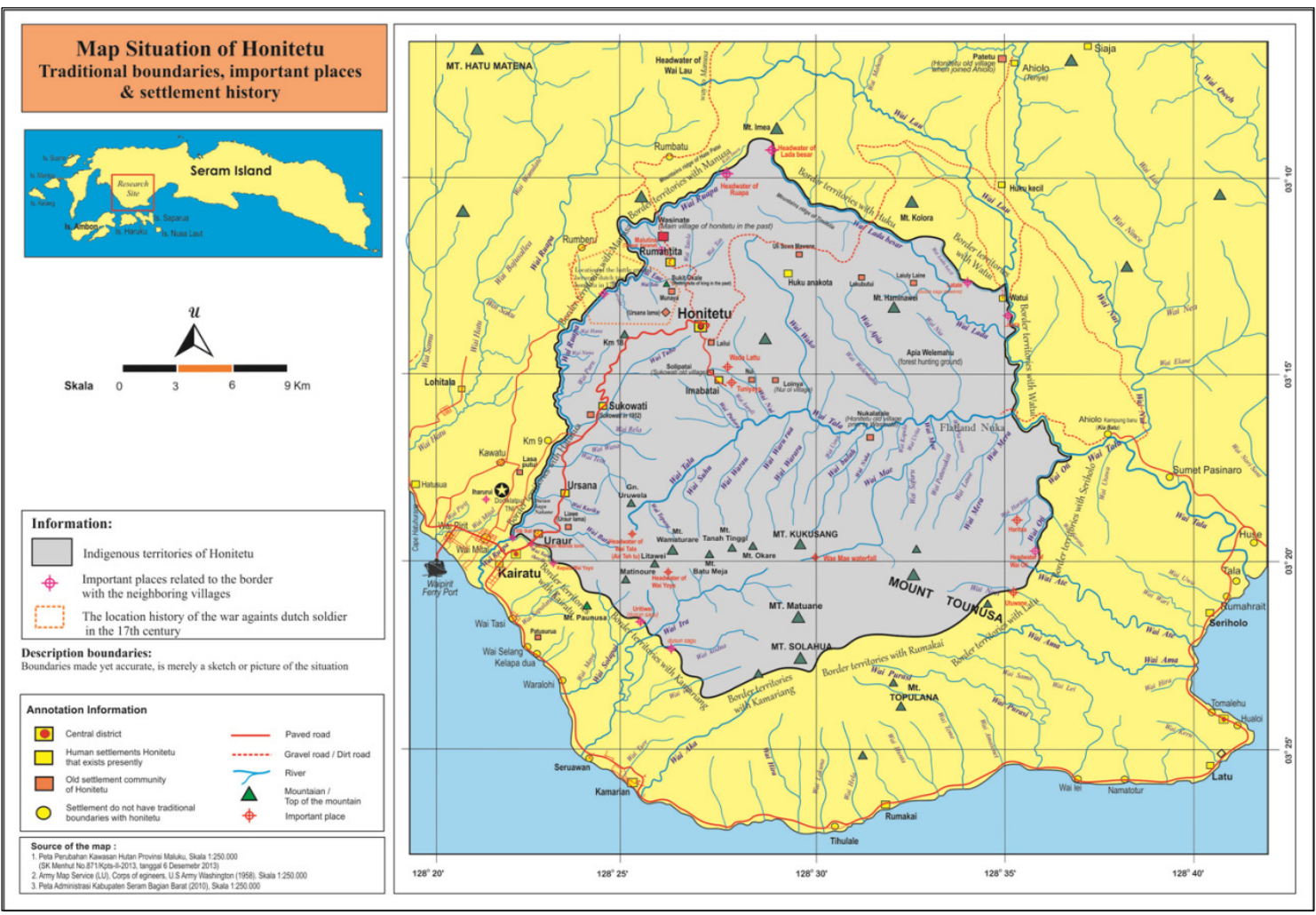

Figure 1. Map of study location 


\subsection{Data Collection and Analysis}

PAR approach [13] was conducted through an in-depth interview process with key informants. The results of in-depth interviews are used to construct meaning constructions between researchers and the community through a group discussion process. The discussion group participants consisted of 4 groups including groups of elderly men, young men, elderly women and young women. Criteria of the old group are Age 35 years - 60 years. Young group is 20 years old $-<35$ years old. Discussion group divisions are intended to gain a shared understanding of the topics discussed. Discussion results in one group will be discussed again in another group repeatedly. Next, it will come to the conclusion of results that can be accepted by the whole society.

The data were analyzed with an approach that refers to the concepts of Greenwood and Levin [13]. Participatory analysis is built to interpret each topic in the discussion arena. Understanding researchers will be processed with the community to get a conclusion of mutually agreed analysis. Stages of analysis are done iteratively throughout the discussion phase. The results of the analysis will help understand moving in the direction of action.

\section{Results and Discussion}

\subsection{Customary System in Forest Product Management}

Forest products are products that naturally grow in forest areas. Forest product management involves regulating the utilization of forest products. Forest products used include wood, rattan, bamboo, roof leaf. Meal needs including sago as staple food. Protein sources from forests include wild boar, deer, fitchew, bats, and various birds and vegetables such as ferns, mushrooms, jungle melinjo, young bamboo shoots etc. Various types of forest leaves, bark and tree roots are used as traditional medicine. Resin damar as oil lamp and gaharu for fragrance.

Forest management systems in the ancestral ages have no special arrangement but the customary territory that claims to an indigenous group can be exploited by all members of the community without any limitations on utilization. Specific rules for harvesting are not fixed beforehand, because the available forest products are still many compared to the number of community needs. This condition shows the existence of knowledge of regeneration faster than utilization

Population growth has increased the number of forest product's needs. Besides that a prominent development for the utilization of forest products on a large scale that is at the time of entry of traders who want to buy forest products. Early purchase system with barter system (exchange with goods). Types of goods exchanged such as machetes, hoes, and other household appliances such as plates, glasses, pans and others. The goods for the community are very helpful for everyday life, such as machetes become a priority because it accelerates the management of forest products. This has prompted people to take more forest products to exchange. The main forest products targeted by traders are originally resins and gaharu, which are widely available in the forests of Seram Island.

Improving the utilization of forest products by indigenous peoples has encouraged the making of customary rules for their utilization arrangements. This shows that indigenous peoples in the past have knowledge of the future of forest products if not managed properly will result in destruction. The rules set are custom sasi in regulating the timing of the harvest of forest products. Sasi is a system that prohibits the taking of certain forest products for a certain period of time in certain areas determined by customary institutional agreements with the community to be known and implemented by all members of the community. Sasi implementation process begins by suggesting the type of plants to be carried out sasi and mention the location of the land and the length of time to be set for sasi. Sasi time is usually determined based on productive time for harvesting of plants or animals so that for one type of plant or animal will have different time sasi. Examples of resin sasi can reach 2-3 years, the animal kusu time sasi can reach 1-2 years. After determining the type, location and time of sasi, then in the field done by marking the sasi by tying the type of plant sasi on wood boards while for animals are marked cross wood on the area to be sasi. Signs are usually placed at the entrance of the location, so everyone passing by knows that sasi is being implemented at that location.

The rules of implementation of the sasi are accompanied by the existence of sanctions. Customary sanctions are imposed in the form of fines and / or disasters that will befall a person who commits a breach of sasi. In ancient times, sasi was done by making a traditional ceremony involving traditional institutional devices and performing traditional ceremonies using betel plant and areca nut. At the ceremony was conducted communication with the ancestors to be involved in the implementation of sasi. The involvement of the ancestors is believed to be an invisible form of control, but if there is a violation it will be known if people experience the disaster. The community believes that there are ancestors who occupy every forest area within the customary territory so it needs to be respected by communicating permits to perform activities in the forest.

Sasi in subsequent developments with the inclusion of Christianity and Islam in indigenous villages on the island of Seram cause the technical implementation of the sasi have changed. The changes include the name of the customary sasi be a sasi church or mosque sasi. The sasi ceremony is performed with prayer in the church or mosque as a form of God's involvement in controlling the sasi. Thus the sanction received by the offender is God's punishment. Fear of God as a new belief of indigenous 
peoples has strengthened the observance of sasi. Another change is a sign on the ground by making a nameplate for example for church sasi, a sign made by writing church sasi on board and placed on the location of plants to be sasi.

In some locations in traditional villages on the island of Seram still apply custom sasi combined with sasi church. Custom sasi usually done in forest location for example in Honitetu do sasi adat for resin or animal, while sasi church usually on the type of agricultural crops such as coconut, cloves, nutmeg and other fruits.

Implementation of church sasi is done by church leaders, but control is done by customary institution. This condition indicates the collaboration between adat and church government that will strengthen the implementation of sasi. Customary institutions established to control natural resources including the implementation of the sasi regulations are called "kewang". Natural resources by indigenous peoples belong to natural resources on land and sea (waters). For that there are institutional Kewang land and sea.

The customary system in establishing the institution of kewang has reflected the existence of a thorough monitoring of natural resources. This is based on the high public dependence on natural resources. The form of dependence is not only on the social system environment of a particular society, but also includes the outside community. Outsiders can take the forest resources owned by certain indigenous peoples. For this reason, the control system has become the indigenous knowledge of indigenous peoples to prevent the loss of forest resources.

At the latest development in Seram Island in facing the issue of indigenous people's demands on land allocation policy by the government is not approved by the community. The public demand is implemented by conducting sasi to the main highway in Seram Island so that all activities are stopped. The implementation of this sasi is used for purposes different from previous sasi objectives covering forest land and plants or animal species. Sasi value here is more directed to the form of prohibition to not conduct any activity with time sasi determined after the demands of indigenous peoples fulfilled. The application of custom sasi still uses traditional ceremony such as sasi initially but the purpose is different. Various changes can occur but the value of the sasi is still relevant ie the rules to prohibit activities or take the results on the land or forest products that are being done sasi.

Sasi becomes a concept to respect indigenous peoples' property rights and maintain social life patterns through the distribution of benefits or outcomes from a balanced use of natural resources. The essence of Sasi is an effort to preserve the social life of the community, including efforts to equal income from natural resources to all citizens or local residents. Therefore, the existence of sasi for the people around the forest is very helpful for the community to improve the welfare of the community and the sustainability of forest resources.

\subsection{Customary System in Forest Land Management}

Different of the management of forest products on the island of Seram also apply to forest land management. Forest land is a forest area used by indigenous peoples by changing the structure and composition of vegetation in forest land. Forest land managed by indigenous peoples on Seram Island begins with planting food crops such as tubers and vegetables. In line with the entry of traders, communities began to manage the land by commercial cultivation. Commercial crops cultivated on forest land belong to annual crops such as cloves, Nutmeg, Coconut, chocolate and various types of fruits.

Stages of forest land management begin by planting food crops among forest plants. Then planting is with a combination of commercial plants. If commercial crops have grown so high, people will leave the land to open new land to grow food crops. Communities have the knowledge that long-life plants that have shaped trees will block the light needed by food crops. In addition, the community also assessed that there will be nutrient competition, so that crops grown are not fertile or low productivity.

Management of shifting forest land to grow food crops is generally a former land overgrown with long-life crops so there is no open land. As for land that is not planted longevity plants are usually managed 4-5 times the harvest and then opened a new land. The soil is allowed to regenerate naturally and form secondary forest. At a certain time the land will be used for planting with long life crops.

Land that has grown longevity plant called "dusung". Dusung is a form of land use with a traditional agroforestry system where agricultural crops grow with some forest plants that are not felled during gardening. Dusung in its development has been modified by creating sub areas for food crops, longevity crops and forest plants that grow naturally. Different types of growing plants have formed a stratified vegetation strata that has ensured the sustainability of land use. In addition, dusung has become a bank for the community because there are harvests throughout the year. This makes the community maintain the system of dusung in managing forest land.

The land management system implements sasi regulations aimed at certain types of crops. For example sasi coconut plant or sasi clove plant. The types of plants are not harvested during the implementation of the sasi. Other types of plants that do not sasi on dusung land can be used anytime. Signs on the dusung usually marked by hanging the type of plant on the board that reads can be done sasi. People who see it will not take the crop because there will be sanctions.

\subsection{Dusung Portrait as a form of Sustainable Forest Land Management}

The portrait dusung taken as an example in this profile is a dusung belonging to one of the families in Honitetu 
village located about $350 \mathrm{~m}$ from the settlement. Dusung was first managed in 1977. Since it began to be managed this dusung never left or never passed the fallow period. The technique used is a crop rotation system that aims to keep the soil fertile and ensure sustainable land use. In addition, this dusung in the opening technique is not done clearing the land (clear cutting) but the existing forest trees on the land are felled in stages in accordance with the development of cultivated species. Forest trees are needed as shade because there are types of plants that require shade. And, also with the consideration the soil does not dry quickly.

Planting pattern follows the rainy season. Types of seasonal crops are usually grown during the rainy season in May and June. But there are also some types of plants planted in December when there is little rain due to the influence of wind from the West Indonesia region that brings a little rain. In this dusung there is always a change of plant species in each growing season that aims to provide nutrients to the soil

There are considerable variations of plant species, both variations of seasonal crop species and longevity crop variations. This is intended to be able to meet the needs of their own consumption and sales needs for family income. This guarantees the use of continuous results. The complete varieties of plant species can be seen in Figure 2.

Spacing varies depending on the type of plant. Seasonal crop spacing about 1 meter or less 1 meter. Often the annual crop is grown alternately like cassava, lemongrass. Sweet potatoes and vegetables are planted in plot form. For fruit plants and long life crops grown with a distance of 4 to 5 meters, setting spacing is intended to obtain maximum yield.

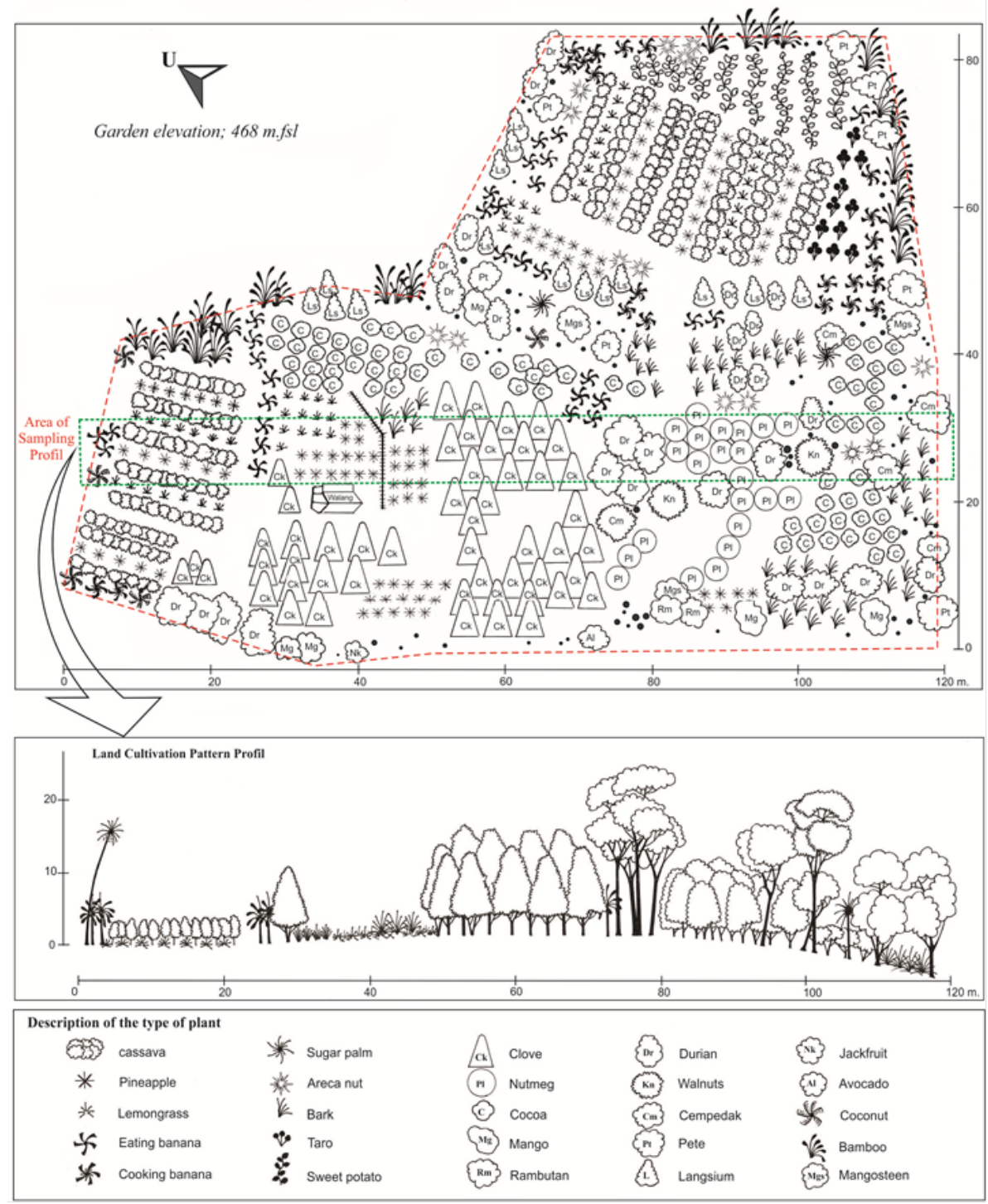

Figure 2. Profile of Dusung 
The area of this garden is about 1 ha. Dusung is limited by several gardens owned by other residents in East, North and West. The marks used as borders are longevity crops such as coconut plants, tamarind trees, and pate trees. Each owner Dusung recognize boundaries with one another so as to avoid any conflict. The absence of conflict provides a guarantee of the security of sustainable use of the skill.

High dependence on the dusung causes willingness and passion to work hard to manage the skill. The community continues to manage the dusung on an ongoing basis because it respects the heritage of the land from the ancestors to be preserved for the next generation. Factors affecting the willingness and spirit to maintain the practice of dusung is a dusung can guarantee the utilization of the results throughout the year with the existence of variations of plants in the dusung. The management of the classification is efficient because it does not require a high cost.

At certain times the rules of sasi apply to some types of plants in dusung especially for fruit crops. Sasi is usually done when the tree is already producing fruit. Sasi is applied because there is not always any control of the dusung. The application of sasi has helped the owner of the dusung to produce the productivity of the dusung in a more effective way because of the control of the sasi with the sanction. The application of widespread sanctions does not look at whether the perpetrators are indigenous or migrant residents. Respect for the rules of sasi is based on the value of shame if punished. In addition there is an unrequited value if the concerned apply sasi will not be violated by others. These values and norms have strengthened the application of sasi.

\subsection{Customary Value in Forest Management Sustainability}

The concept of sustainable forest management developed by the ITTO (International Tropical Timber Organization), in 1990, at a conference in Bali, covers the sustainability of economic, social and ecological benefits. The system of forest land use (dusung) and management of forest products is based on the value of local wisdom developed by the community aimed at maintaining sustainable use. Variations of plant species (short-lived crops and long-life crops) developed on the skeleton ensure the sustainability of the results utilized throughout the year. The stratification of plant species on the dusung and the treatment of the crop rotation system ensure the ecological sustainability of the land. Local knowledge and rules imposed Sasi ensure the sustainability of social systems. The internalized social system is an ancestral heritage to be used by the next generation.

Arrangement of sasi rules is a form of adaptation to changes in forest conditions to regulate the protection of forest products and the maximum utilization of products.
The relevance of sasi with sustainable forest management lies in the time of harvesting the results, such as the dammar sasi. People are prohibited from harvesting resin for a period of 1 year. This time period has given the dammar tree an opportunity to produce more sap. It also provides regeneration opportunities for nearby plant and animal species that occupy forest areas. In the dusung, Implementasi sasi also contribute to increase the income of the community because the special crop yields for the longevity crop is more leverage.

The rules of sasi shall be accompanied by the stipulation of sanctions in the event of a violation. Sanctions can be fines and natural punishments in the form of disasters that befall the person who violates. The value of obedience and shame, if sanctioned, has strengthened the enforcement of the rules of sasi. Society considers sasi also for personal or group interests. Community participation through deliberations in the formulation of regulations has ensured compliance with this rule because there is agreement from all members of the community. In addition, the sustainability of forest management is also supported by the high dependence of indigenous peoples on forests and the continued existence of hereditary heritage.

The various customary systems that have been developed in forest and land management of indigenous peoples on Seram Island have shown an adaptation to the various conditions affecting the social system of communities in managing forest and land products. Changes that occur in indigenous peoples are always accompanied by the establishment of rules governing the sustainability of the utilization of forest products

Sasi rules set to be a guarantee of sustainable forest management. The value of the adherence found to the community for this customary sasi rule is the maximum benefit of the forest products to be harvested and the value of feeling embarrassed if punished. It has strengthened the customary sasi which is enforced. The belief in the rules and the role of sanction becomes an element to control the implementation of the customs rules. The value of obedience and shame, if sanctioned, has strengthened the enforcement of the rules of sasi. Society considers sasi also for personal or group interests. Community participation through deliberations in the formulation of regulations has ensured compliance with this rule because there is agreement from all members of the community. In addition, the sustainability of forest management is also supported by the high dependence of indigenous peoples on forests and the continued existence of hereditary heritage.

The community considers the importance of rules that all members of society can adhere to. Community participation through deliberation in the formulation of rules by all members of the community has ensured compliance with these rules because there has been agreement from all members of the community. The 
legitimacy of indigenous peoples' rules of sustainable forest management is a lesson of shared values built by the community to continue to apply the rules.

The sustainability of forest management is supported by indigenous peoples' dependence on forests. The forms of dependence are, among other things, the economic, socio-cultural and ecological values of forest land utilized. The community recognizes that these values will support the benefits that society receives today and for the next generation. Attention to the sustainability of forest resources for the next generation has built togetherness values that form the harmonious norm of relationships between families and groups. Values and norms as well as forming the community's compliance with rules applicable to land use systems.

The relevance of sasi with sustainable forest management lies in the timing of harvesting of forest products, for example sasi forest damar. Communities are forbidden to harvest resin for a period of 1 year. This time period has given the resin tree an opportunity to produce more sap. In addition it provides regeneration opportunities for the surrounding plant species and animals that occupy the forest area. Implementation of sasi also contributes to increase people's income because of the maximum harvest.

\subsection{Strengthening Indigenous Peoples for Sustainable Forest Management}

The reinforcement intended in this paper is a PAR process to formulate actions that will be undertaken by indigenous peoples in the face of factors that threaten sustainable forest management. Customary systems that have been maintained by communities to ensure the sustainability of forest management still require special reinforcement on the factors that have been maintained to date.

Strengthening the sustainability of economic benefits is aimed at anticipating outsiders' access to the benefits of forest products (traders, enterprises etc.). External access can reduce the utilization of forest products by communities and even threaten ecological sustainability due to over exploitation. Sustainability strengthening is anticipated by the concept of sasi. The purpose of sasi is to maximize the benefits of forest products.

Changes in the use of forest products from subsistence to commercial have affected the use of forest land to be managed by growing commercial crops. However, various forms of forest land use and forest products by indigenous peoples have been limited by the provision of sasi so that outsiders and indigenous peoples themselves are responsible for complying with the agreed rules. Changing the rules and objectives of customary systems for sustainable forest management poses challenges faced by indigenous peoples as well as communities working with indigenous peoples.
The challenge is to change the values found in the community. The elements affecting the strengthening of the value of compliance to the rules include agreements in the making of rules (participatory elements); Rules to benefit the entire community (economic sustainability) and increased yields of forest resources (ecological sustainability).

The rules of sustainable forest management have the support of indigenous peoples because in each indigenous community of Seram Island has a high dependence on forest resources located in the customary territory of a village. Outside party intervention is a challenge to maintain these values because people will move cognitively to influence the social structure that drives community relations with forests.

The function of controlling forest resources in the institutional structure of custom is done by kewang or often referred to as forest police. Kewang plays a role in controlling the rules set by the customary government in relation to forest resources. Currently, kewang is not performing its function maximally due to time constraints and wide area coverage. For that purpose the control function is supported by other institutional devices even by all landowners (clans and individuals). The overall control function built in society is based on values and norms that shape the behavior of society which is the institutional element [14].

The role of the institution as a controller that includes the rules, norms and values that have been built since the ancestors despite having undergone changes but the most important function is to continue to strengthen the capacity of the community. In this case the strengthening of society is intended to make the institute as the foundation. Outside party interventions will be determined on the community itself that ensures the sustainability of the customary system. Learning the practice of dusung is a dynamic but highly appropriate process of strengthening to maintain economic, social and ecological functions. In the profile picture shows the existence of plant stratification that allows the existence of ecological protection of the soil.

\section{Conclusions}

The learning of indigenous systems in the management of forest and land products in indigenous peoples shows a sustainable use system. Implementation of sasi and sanction rules has increased the quantity and quality of food crops and encourages the conservation of biological resources and ecosystems. While the dusung system can limit the clearing of forest land, the pattern of dusung also provides an opportunity to create a forest ecosystem that is similar to the primary forest ecosystem because it consists of various layers of strata with various types of plants in it. 
Changes to the rules of sasi and the dusung system are forms of adaptation that can change the way and the purpose but the values of dusung and sasi are still growing for the purpose of protection of forest and land products for sustainable use. These values are based on high dependence on forest and land products. Inheritance of utilization for the next generation becomes the main principle of indigenous people's togetherness.

The strengthening action of the land use system provides a new commitment for the community to organize and strengthen the customary system that functions to control the area and the potential of land for the sustainability of forest utilization.

Sustainable forest management created on the basis of scientific knowledge should be adapted to local circumstances, including the biophysical state of the forest, the economy and socio-cultural circumstances of the community.

\section{REFERENCES}

[1] Ashenafi ZT, Williams NL. 2005. Indigenous Common Property Resource Management in the Central Highlands of Ethiopia. Human Ecology Vol 33.

[2] Moeliono M, Wollenberg E, Limberg G. 2008. Decentralization of Forest Governance: Politics, Economics and the Struggle to Take Forest in Kalimantan, Indonesia. Bogor. Center for International Forestry Research (CIFOR).

[3] Suharjito D, Khan A, Djatmiko WA, Sirait MT, Evelyna S. 2000. Characteristics of Community-Based Forest Management. FKKM-Ford Foundation. Yogyakarta: Aditya Media.

[4] Soetarto E, 2012. The Cause of Conflict Government Policy Does Not Proceed To The People. Paper at the Seminar of Agrarian Conflict. Yogyakarta
[5] Adnan H, Tadjudin D, Yuliani EL, Komarudin H, Lopulalan D, Siagian YL, Munggoro DW. 2008. Learning from Bungo Managing Natural Resources in the Decentralization Era. Bogor: Center for International Forestry Research (CIFOR).

[6] Suharjito D, Saputro GE. 2008. Social Capital in Forest Resource Management at Kasepuhan Community, Banten Kidul. Journal of Forest Social and Economic Research Vol 5 No. 4: 317-335. Bogor: Center for Socio-Economic Research and Forestry Policy Forestry Research and Development Agency Ministry of Forestry

[7] Gunarso P, Setyawati T, Sunderland T, Shackleton C (ed). 2009. Forest Resource Management in the Decentralization Era: Lessons Learned from Malinau Research Forest, East Kalimantan, Indonesia. Bogor: Center for International Forestry Research (CIFOR).

[8] Martin E, 2016. Cultural Capital of Farmers in Forest Preservation: Phenomenological Studies of Semende People in the Highlands of South Sumatra. Dissertation of Doctoral Program of Forest Management Science IPB Bogor Postgraduate Program: Not Published

[9] Suharjito D. 2013. Agrarian Reform in the Forestry Sector: Realizing Sustainable Forest Management, Social Justice and Nation prosperity in Kartodhiharjo (ed) 2013. Return to Straight Path. FORCI Development Publisher.

[10] Sunderlin, W.D., Angelsen, A., Belcher, B., Burgers, P., Nasi, R., et al., 2005. Livelihoods, forests, and conservation in developing countries: an overview. World Dev. 33, 13831402 .

[11] Nugraha A, Murtijo, 2005. Forest anthropology. Wana Aksara Publisher. Banten Indonesia.

[12] Geertz C, 1985Agricultural Involution, Ecological Change Process in Indonesia. Yayasan Obor Indonesia Jakarta.

[13] Greenwood DJ, Levin M. 1998. Introduction to Action Research. Social Research for Social Change. Sage Publication, Inc.

[14] Uphoff N. 1992. Local Institutions and Participation for Sustainable Development. Gatekeeper Series No. 31. 